Pacific Journal of Mathematic 


\title{
ON A THEOREM OF ORLICZ AND PETTIS
}

\author{
Charles W. McArthur
}

In this paper a direct proof of the following theorem of Orlicz, Pettis, and Grothendieck is given.

Theorem 1. In a locally convex Hausdorff space each subseries of a series converges with respect to the initial topology of the space if and only if each subseries of the series converges with respect to the weak topology of the space.

In a second theorem each of three additional conditions is shown to be equivalent to subseries convergence in complete locally convex Hausdorff spaces. Two of these equivalence are known for Banach spaces. The third condition, a weak compactness condition on the unordered partial sums of the series, is new even for Banach spaces. It is a consequence of the first theorem that a weak unconditional basis for a weak sequentially complete locally convex Hausdorff space is an unconditional basis.

Theorem 1 was first proved by Orlicz [8, Satz 2] for weakly sequentially complete Banach spaces. Banach [1, p. 240] noted the hypothesis of weak sequential completeness was unnecessary. A proof of Theorem 1 for Banach spaces was given by Pettis [9, Th. 2.32]. Grothendieck [4, Cor. 2, p. 141] obtains Theorem 1 for locally convex spaces as a special case of a theorem on vector valued integrals.

The proof of Lemma 3 was suggested by the referee in place of a longer proof by the author. It uses a result of a paper of James [5] which appeared after this paper was submitted.

For clarity we now state the basic definitions in more detail. If $E$ is a Hausdorff linear topological space with topology $\mathscr{T}$ then a series $\sum_{i=1}^{\infty} x_{i}$ in $E$ is subseries convergent relative to $\mathscr{T}$ if and only if:

(A) Corresponding to each subseries $\sum_{i=1}^{\infty} x_{k_{i}}$ there is an element $x \in E$ such that $\lim _{n} \sum_{i=1}^{n} x_{k_{i}}=x$, the convergence being relative to $\mathscr{T}$.

Let $E^{*}$ denote the space of $\mathscr{T}$-continuous linear functionals on $E$. Then $\sum_{i=1}^{\infty} x_{i}$ is weak subseries convergent if and only if:

(B) $\sum_{i=1}^{\infty} x_{i}$ is subseries convergent relative to the $w\left(E, E^{*}\right)$ topology for $E$.

For a series $\sum_{i=1}^{\infty} x_{i}$ in a linear topological space $(E, \mathscr{T})$ let $S=\left\{\sum_{i \in_{\sigma}} x_{i}: \sigma\right.$ finite $\}$ and consider the following conditions where $\overline{\mathrm{sp}}\left\{x_{i}\right\}$ denotes the closure, relative to $\mathscr{T}$, of the linear span of $\left\{x_{i}\right\}$ :

(C) $S$ is totally bounded relative to $\mathscr{T}$. 
(D) Whenever $\left\{f_{n}\right\}$ is an equicontinuous sequence in $E^{*}$ such that $f_{n}(x) \rightarrow 0$ for all $x \in \overline{\mathrm{sp}}\left\{x_{i}\right\}$ then $f_{n}(x) \rightarrow 0$ uniformly on $S$.

(E) The $w\left(E, E^{*}\right)$ closure of $S$ is $w\left(E, E^{*}\right)$ compact.

In this paper we also prove,

THEOREM 2. For a series in a locally convex, complete, Hausdorff space the conditions $(\mathrm{A}),(\mathrm{B}),(\mathrm{C}),(\mathrm{D})$, and $(\mathrm{E})$ are equivalent.

The equivalence of (A), (B), (C), and a variant of (D) for series in Banach spaces is known (see, e.g., [7]).

\section{Proof of Theorem 1 .}

LEMma 1. If $\sum_{i=1}^{\infty} x_{i}$ is a series in a locally convex Hausdorff space $E$ which satisfies the condition (D) then it is subseries Cauchy.

Proof. We first observe that if $M \subset E$, then $M$ is bounded if, whenever $\left\{f_{n}\right\}$ is an equicontinuous sequence in $E^{*}$ such that $\lim f_{n}(x)=0$ for all $x \in E$, it follows that $\lim f_{n}(x)=0$ uniformly on $M$. For if $M$ is not bounded and $U$ is a closed convex circled neighborhood of zero that does not absorb $M$, then for each integer $n$ there is an $f_{n} \in E^{*}$ and an $x_{n} \in M$ such that $\left|f_{n}(x)\right| \leqq 1 / n$ on $U$ and $f_{n}\left(x_{n}\right) \geqq 1$. The sequence $\left\{f_{n}\right\}$ is equicontinuous and $\lim f_{n}(x)=0$ on $E$ but not uniformly on $M$. We observe further that if $\sum_{i=1}^{\infty} x_{i}$ satisfies condition (D) then $S$ is bounded from which it follows that $\sum_{i=1}^{\infty}\left|f\left(x_{i}\right)\right|<+\infty$ for each $f \in E^{*}$.

We now prove Lemma 1 by showing that if $\sum_{i=1}^{\infty} x_{i}$ is not subseries convergent and $\sum_{i=1}^{\infty}\left|f\left(x_{i}\right)\right|<+\infty$ for each $f \in E^{*}$ then condition (D) does not hold. Suppose there exists a subseries $\sum_{i=1}^{\infty} x_{k_{i}}$ whose sequence of partial sums $\left\{\sum_{i=1}^{n} x_{k_{i}}\right\}$ is not a Cauchy sequence. Thus there exists a closed convex circled neighborhood $V$ of zero and an increasing sequence $\left\{p_{n}\right\}$ of positive integers such that for each $n$,

$$
s_{n}=\sum_{i=p_{n}+1}^{p_{n+1}} x_{k_{i}} \notin V .
$$

Then, $\left[6,14.4\right.$, p. 119] for each $n$ there exists an element $f_{n} \in E^{*}$ such that $f_{n}\left(s_{n}\right)=1$ and $\sup \left\{\left|f_{n}(x)\right|: x \in V\right\}<1$. Thus the sequence $\left\{f_{n}\right\}$ is equicontinuous. Since $\left\{f_{n}\right\}$ is equicontinuous it is pointwise bounded on $E$. Using this and the diagonal process we select a subsequence $\left\{f_{n_{m}}\right\}$ which has $\left[6,17.4\right.$, p. 155] a $w^{*}$-cluster point $f_{0}$ with the property that $\lim _{m} f_{n_{m}}(x)=f_{0}(x), x \in \overline{\mathrm{sp}}\left[x_{i}\right]$. From the hypothesis (D) we have that $\lim _{m} f_{n_{m}}(x)=f_{0}(x)$ uniformly for $x \in S$. Given $\varepsilon>0$ there exists $N$ such that 


$$
\sum_{i=N}^{\infty}\left|f_{0}\left(x_{i}\right)\right|<\varepsilon / 2 .
$$

Thus, for $m$ sufficiently large, $\left|f_{0}\left(s_{n_{m}}\right)\right|<\varepsilon / 2$. Now there exists $N^{\prime}>N$ such that if $m \geqq N^{\prime}$ then $\left|f_{n_{m}}(x)-f_{0}(x)\right|<\varepsilon / 2$ for all $x \in S$. Thus, for $m$ sufficiently large,

$$
\left|f_{n_{m}}\left(s_{n_{m}}\right)\right| \leqq\left|f_{n_{m}}\left(s_{n_{m}}\right)-f_{0}\left(s_{n_{m}}\right)\right|+\left|f_{0}\left(s_{n_{m}}\right)\right|<\varepsilon
$$

but this contradicts $f_{n_{m}}\left(s_{n_{m}}\right)=1$ for all $m$.

It is well known $[6,17.8$, p. 156] that each weakly compact subset of a locally convex space is complete. The proof of the following lemma follows the same line of argument as the above mentioned result, so is omitted.

Lemma 2. Let $(E, \mathscr{T})$ be a locally convex space. If $\left\{x_{\alpha}\right\}$ is a Cauchy net in $E$ relative to the topology $\mathscr{T}$ and if $x \in E$ is a $w\left(E, E^{*}\right)$-cluster point of $\left\{x_{\alpha}\right\}$ then $x_{\alpha} \rightarrow x$ in the topology $\mathscr{T}$.

Proof of Theorem 1. It is clear that (A) implies (B). We now assume (B) and show that (A) follows. It is clear that when (B) holds we have $\sum_{i=1}^{\infty}\left|f\left(x_{i}\right)\right|<+\infty$ for each $f \in E^{*}$, i.e., $\left\{f\left(x_{i}\right)\right\}_{i=1}^{\infty}$ is an element of $(l)$ for each $f \in E^{*}$. The space $(l)$ here is either real or complex depending on whether the scalar field of $E$ is real or complex. For either real or complex $(l)$ sequential convergence in the $w\left((l),(l)^{*}\right)$ topology for $(l)$ implies convergence in the norm topology of $(l)$ and elements of the form $\left\{\varepsilon_{i}\right\}$, where $\varepsilon_{i}= \pm 1$ or 0 , are fundamental in $(l)^{*}$. Let $\left\{f_{n}\right\}$ be an arbitrary sequence in $E^{*}$ such that $\lim _{n} f_{n}(x)=0$ for all $x \in \overline{\mathrm{sp}}\left\{x_{i}\right\}$. Let $\lambda_{n}=\left\{f_{n}\left(x_{i}\right)\right\}_{i \in \omega}$. We will show, following Pettis [9], that

(F) $\lim _{n} \sum_{i=1}^{\infty}\left|f_{n}\left(x_{i}\right)\right|=0$, i.e., $\lambda_{n} \rightarrow 0$ in the norm topology of (l), by showing that

$$
\lim _{n} \sum_{i=1}^{\infty} \varepsilon_{i} f_{n}\left(x_{i}\right)=0
$$

for each sequence $\left\{\varepsilon_{i}\right\}$, where $\varepsilon_{i}= \pm 1$ or 0 . For such a sequence $\left\{\varepsilon_{i}\right\}$ let $\sigma+=\left\{i: \varepsilon_{i} \geqq 0\right\}$ and $\sigma-=\left\{i: \varepsilon_{i}<0\right\}$. By (B) there exist $x_{\sigma+}$ and $x_{\sigma_{-}}$such that $f\left(x_{\sigma+}\right)=\sum_{i \epsilon_{\sigma+}} f\left(x_{i}\right)$ and $f\left(x_{\sigma_{-}}\right)=\sum_{i \in_{\sigma_{-}}} f\left(x_{i}\right)$ for all $f \in E^{*}$. Now $x_{\sigma_{+}}$and $x_{\sigma_{-}}$are elements of $\overline{\mathrm{sp}}\left[x_{i}\right]$. Suppose $x_{\sigma_{+}} \notin \overline{\mathrm{sp}}\left[x_{i}\right]$. Then there exists $f \in E^{*}$ such that $f\left(x_{\sigma+}\right) \neq 0$ and $f(x)=0$ for $x \in \overline{\operatorname{sp}}\left[x_{i}\right]$. This, however, implies the contradiction $f\left(x_{\sigma_{+}}\right)=0$ since $f\left(x_{\sigma_{+}}\right)=$ $\sum_{i \in \sigma+} f\left(x_{i}\right)$ where $x_{i} \in \overline{\operatorname{sp}}\left[x_{i}\right]$. Hence, it follows that

$$
\lim _{n} \sum_{i=1}^{\infty} \varepsilon_{i} f_{n}\left(x_{i}\right)=\lim _{n} f_{n}\left(x_{\sigma_{+}}-x_{\sigma_{-}}\right)=0 .
$$


Thus we have shown that $(F)$ holds, from which it is evident that $\lim _{n} f_{n}(x)=0$ uniformly for $x \in S$. It now follows, by Lemma 1 , that $\sum_{i=1}^{\infty} x_{i}$ is subseries Cauchy. Then from (B) and Lemma 2, $\sum_{i=1}^{\infty} x_{i}$ is subseries convergent.

\section{Proof of Theorem 2.}

Lemma 3. Let $E$ be a complete Hausdorff locally convex space and let $E_{0}$ be a closed separable subspace of $E$. Let $M$ be a subset of $E_{0}$ such that whenever $\left\{f_{n}\right\}$ is an equicontinuous sequence in $E^{*}$ such that $\lim _{n} f_{n}(x)=0$ for all $x \in E_{0}$ it follows that $\lim _{n} f_{n}(x)=0$ uniformly for $x \in M$. Then the weak closure of $M$ is $w\left(E, E^{*}\right)$ compact.

Proof. If the weak closure of $M$ is not weakly compact then, by the result of James [5, Condition (9), p. 104], there is a positive number $\varepsilon$, an equi-continuous sequence $\left\{f_{n}\right\}$, and a sequence $\left\{z_{n}\right\}$ from the weak closure of $M$ such that

$$
\left|f_{n}\left(z_{k}\right)\right|>\varepsilon \text { if } n \leqq k \text { and } f_{n}\left(z_{k}\right)=0
$$

if $n>k$. Let $\left\{x_{n}\right\}$ denote a sequence in $E_{0}$ which is dense in $E_{0}$. Using the diagonal technique we select a subsequence $\left\{f_{n_{j}}\right\}$ of $\left\{f_{n}\right\}$ which has a $w^{*}$-cluster point $f_{0}$ such that $\lim _{j} f_{n_{j}}\left(x_{m}\right)=f_{0}\left(x_{m}\right), m \in w$. Hence, $\lim _{j} f_{n_{j}}(x)=f_{0}(x)$ for all $x \in E_{0}$. We then have from the uniformity hypothesis that $\lim _{j} f_{n_{j}}(x)=f_{0}(x)$ uniformly for $x \in M$ and hence uniformly for $x$ in the weak closure of $M$. Since $z_{k}$ is in the weak closure of $M$ this contradicts the fact that $\left|f_{n_{j}}\left(z_{k}\right)\right|>\varepsilon$ if $n_{j} \leqq k$ and $f_{n_{j}}\left(z_{k}\right)=0$ if $n_{j}<k$.

Lemma 4. For a series $\sum_{i=1}^{\infty} x_{i}$ in a locally convex Hausdorff space E, (A) implies (C) implies (D) and (E) implies (B).

Proof. (A) implies (C): Subseries convergence implies unordered convergence $[2$, p. 59]. Let $U$ be a neighborhood of 0 . Then there exists a finite set $\sigma_{0}$ of positive integers such that if $\sigma$ is a finite subset of positive integers and $\sigma \supset \sigma_{0}$ then

$$
\sum_{i \in \sigma} x_{i}-\sum_{i \in \sigma_{0}} x_{i} \in U
$$

Let $B=\left\{\sum_{i \in o} x_{i}: \sigma \subset \sigma_{0}\right\} \cup\{0\}$. Observe that $B$ is a finite set and for an arbitrary finite subset $\sigma$ of positive integers

$$
\sum_{i \in \sigma} x_{i} \in B+U \text {. }
$$


(C) implies (D): In general totally bounded sets are bounded. Also $[6,8.17$, p. 76$]$ an equicontinuous family of linear functionals on $E$ which converges pointwise on a totally bounded set to an element $f \in E^{*}$ converges uniformly to $f$ on that set. (E) implies (B): If $\sum_{i=1}^{\infty} x_{k_{i}}$ is any subseries and $y$ is a $w\left(E, E^{*}\right)$ cluster point of $\left\{\sum_{i=1}^{n} x_{k_{i}}\right\}$, then $y$ is a $w\left(E, E^{*}\right)$ sum of $\sum_{i=1}^{\infty} x_{k_{i}}$, since if

$$
\left|f\left(\sum_{i=1}^{N} x_{k_{i}}\right)-f(y)\right|<\frac{1}{2} \varepsilon
$$

and

$$
\sum_{i=k_{N}}^{\infty}\left|f\left(x_{i}\right)\right|<\frac{1}{2} \varepsilon
$$

then

$$
\left|f\left(\sum_{i=1}^{n} x_{k_{i}}\right)-f(y)\right|<\varepsilon
$$

if $n>N$.

Proof of Theorem 2. By Lemma 3, (D) implies (E). By Lemma 4, (E) implies (B). Conditions (A) and (B) are equivalent by Theorem 1. By Lemma 4, (A) implies (C) and (C) implies (D).

4. Applications. Suppose that $A$ is a set, that $\sum$ is a $\sigma$-field of subsets of $A$, and $m$ is an additive set function defined on $\sum$ with values in a locally convex Hausdorff space $E$. Then $m$ is weakly countably additive if and only if

$$
\sum_{i=1}^{\infty} f m\left(A_{i}\right)=f m\left(\bigcup_{i=1}^{\infty} A_{i}\right)
$$

for each $f \in E^{*}$ and each sequence of disjoint sets $A_{i}$ in $\sum$. As an immediate consequence of Theorem 1 , we obtain

CoRollary 1. A weakly countable additive set function $m$ defined on a $\sigma$-field $\Sigma$ with values in a locally convex Hausdorff space is countably additive.

Corollary 1 is a generalization of a theorem of Pettis [9, Th. 2.4; 3, Th. 1, p. 318] for Banach space valued set functions.

A sequence $\left\{x_{i}\right\}$ in a Hausdorff linear topological space $(E, \mathscr{T})$ is a basis if and only if corresponding to each $x \in E$ there is a unique sequence of scalars $\left\{a_{i}\right\}$ such that $x=\lim _{n} \sum_{i=1}^{n} a_{i} x_{i}$, the convergence relative to $\mathscr{T}$. A basis is unconditional if for each $x \in E$ every 
rearrangement of the basis expansion for $x$ converges. It is known that a sequence $\left\{x_{i}\right\}$ in a locally convex, metrizable, complete space $(E, \mathscr{T})$ is a basis relative to $\mathscr{T}$ providing it is a basis relative to the $w\left(E, E^{*}\right)$ topology for $E$. As a corollary to Theorem 1 we obtain the following weak basis theorem which applies to a class of linear topological spaces which includes certain nonmetrizable spaces.

CoRollary 2. If $(E, \mathscr{T})$ is a locally convex Hausdorff space which is sequentially complete in its $w\left(E, E^{*}\right)$ topology, then a sequence $\left\{x_{i}\right\}$ in $E$ is an unconditional basis for $(E, \mathscr{T})$ provided it is an unconditional basis for $E$ with its $w\left(E, E^{*}\right)$ topology. Thus, a $w\left(E, E^{*}\right)$ unconditional basis in a semireflexive space $(E, \mathscr{T})$, e.g., a Montel space, is an unconditional basis relative to $\mathscr{T}$.

Proof. Suppose $\left\{x_{i}\right\}$ is a $w\left(E, E^{*}\right)$ unconditional basis. For $x \in E$ let $\left\{a_{i}\right\}$ denote the unique sequence of scalars such that for all $f \in E^{*}$ $f(x)=\sum_{i=1}^{\infty} a_{i} f\left(x_{i}\right)$ where the convergence of the series is unconditional. Unconditional convergence of a series of real or complex numbers implies subseries convergence for that series. It follows, using the hypothesis of $w\left(E, E^{*}\right)$ sequential completeness, that $\sum_{i=1}^{\infty} \alpha_{i} x_{i}$ is weak subseries convergent so by Theorem $1, x=\lim _{n} \sum_{i=1}^{n} a_{i} x_{i}$, convergence relative to $\mathscr{T}$. If $x$ also has the expansion $x=\lim _{n} \sum_{i=1}^{n} b_{i} x_{i}$, unconditional convergence relative to $\mathscr{T}$, then $f(x)=\sum_{i=1}^{\infty} b_{i} f\left(x_{i}\right), f \in E^{*}$ where the convergence is unconditional in the scalar field so $b_{i}=a_{i}$, $i \in \omega$, because of the assumed uniqueness of $\left\{a_{i}\right\}$.

\section{REFERENCES}

1. S. Banach, Théorie des opérations linéaires, Warsaw, 1932.

2. M. M. Day, Normed Linear Spaces, Ergebnisse der Mathematik, Berlin-GöttingenHeidelberg, Springer-Verlag, 1958.

3. N. Dunford and J. T. Schwartz, Linear Operators. Part I, New York, Interscience Publishers, Inc., 1958.

4. A. Grothendieck, Sur les applicationes linéaires faiblement compactes d'espaces $(C K)$, Canad. J. Math. 5 (1953), 129-173.

5. R. C. James, Weak compactness and reflexivity, Israel J. Math. 2 (1964), 101-119.

6. J. L. Kelley and I. Namioka, Linear Topological Spaces, D. Van Nostrand, New York, 1963.

7. C. W. McArthur, A note on subseries convergence, Proc. Amer. Math. Soc. 12 (1961), 540-545.

8. W. Orlicz, Beiträge zur Theorie der Orthogonalentwicklungen, II Studia Math. 1 (1929), 241-255.

9. B. J. Pettis, On integration in vector spaces, Trans. Amer. Math. Soc. 44 (1938). 277-304.

Received June 17, 1965. This research was supported by National Science Foundation Grant No. NSF-GP-2179. 


\section{PACIFIC JOURNAL OF MATHEMATICS}

\section{EDITORS}

\section{H. SAMELSON}

Stanford University

Stanford, California

J. P. JANS

University of Washington

Seattle, Washington 98105

\section{J. DugundJI}

University of Southern California Los Angeles, California 90007

RICHARD ARENS

University of California

Los Angeles, California 90024

\section{ASSOCIATE EDITORS}

E. F. BECKENBACH
B. H. NeUmanN

\section{SUPPORTING INSTITUTIONS}

UNIVERSITY OF BRITISH COLUMBIA CALIFORNIA INSTITUTE OF TECHNOLOGY

UNIVERSITY OF CALIFORNIA

MONTANA STATE UNIVERSITY

UNIVERSITY OF NEVADA

NEW MEXICO STATE UNIVERSITY

OREGON STATE UNIVERSITY

UNIVERSITY OF OREGON

OSAKA UNIVERSITY

UNIVERSITY OF SOUTHERN CALIFORNIA

\author{
STANFORD UNIVERSITY \\ UNIVERSITY OF TOKYO \\ UNIVERSITY OF UTAH \\ WASHINGTON STATE UNIVERSITY \\ UNIVERSITY OF WASHINGTON \\ AMERICAN MATHEMATICAL SOCIETY \\ CHEVRON RESEARCH CORPORATION \\ TRW SYSTEMS \\ NAVAL ORDNANCE TEST STATION
}

Mathematical papers intended for publication in the Pacific Journal of Mathematics should be typewritten (double spaced). The first paragraph or two must be capable of being used separately as a synopsis of the entire paper. It should not contain references to the bibliography. Manuscripts may be sent to any one of the four editors. All other communications to the editors should be addressed to the managing editor, Richard Arens at the University of California, Los Angeles, California 90024.

50 reprints per author of each article are furnished free of charge; additional copies may be obtained at cost in multiples of 50 .

The Pacific Journal of Mathematics is published monthly. Effective with Volume 16 the price per volume ( 3 numbers) is $\$ 8.00$; single issues, $\$ 3.00$. Special price for current issues to individual faculty members of supporting institutions and to individual members of the American Mathematical Society: $\$ 4.00$ per volume; single issues $\$ 1.50$. Back numbers are available.

Subscriptions, orders for back numbers, and changes of address should be sent to Pacific Journal of Mathematics, 103 Highland Boulevard, Berkeley 8, California.

Printed at Kokusai Bunken Insatsusha (International Academic Printing Co., Ltd.), 7-17, Fujimi 2-chome, Chiyoda-ku, Tokyo, Japan.

\section{PUBLISHED BY PACIFIC JOURNAL OF MATHEMATICS, A NON-PROFIT CORPORATION}

The Supporting Institutions listed above contribute to the cost of publication of this Journal, but they are not owners or publishers and have no responsibility for its content or policies. 


\section{Pacific Journal of Mathematics}

\section{Vol. 22, No. $2 \quad$ February, 1967}

Paul Frank Baum, Local isomorphism of compact connected Lie groups ....

Lowell Wayne Beineke, Frank Harary and Michael David Plummer, On the

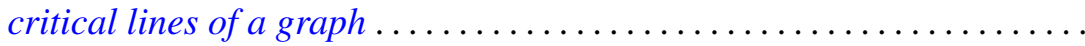

Larry Eugene Bobisud, On the behavior of the solution of the telegraphist's equation for large velocities .......................... 213

Richard Thomas Bumby, Irreducible integers in Galois extensions . . . . . . 221

Chong-Yun Chao, A nonimbedding theorem of nilpotent Lie algebras ..... 231

Peter Crawley, Abelian p-groups determined by their Ulm sequences ...... 235

Bernard Russel Gelbaum, Tensor products of group algebras ........... 241

Newton Seymour Hawley, Weierstrass points of plane domains .......... 251

Paul Daniel Hill, On quasi-isomorphic invariants of primary groups . . . . . 257

Melvyn Klein, Estimates for the transfinite diameter with applications to confomral mapping ................................ 267

Frederick M. Lister, Simplifying intersections of disks in Bing's side approximation theorem ............................. 281

Charles Wisson McArthur, On a theorem of Orlicz and Pettis ........... 297

Harry Wright McLaughlin and Frederic Thomas Metcalf, An inequality for

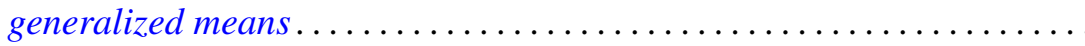

Daniel Russell McMillan, Jr., Some topological properties of piercing

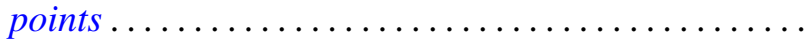

Peter Don Morris and Daniel Eliot Wulbert, Functional representation of topological algebras .

Roger Wolcott Richardson, Jr., On the rigidity of semi-direct products of Lie algebras..................................

Jack Segal and Edward Sandusky Thomas, Jr., Isomorphic

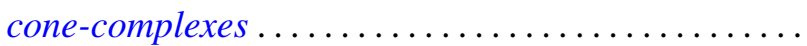

Richard R. Tucker, The $\delta^{2}$-process and related topics.... 